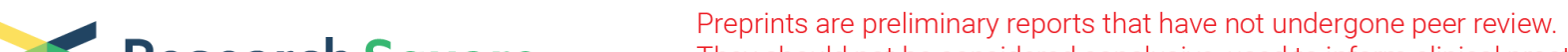 Research Square
or referenced by the media as validated information.
}

\section{Shock response and degassing reactions of calcite at planetary impact conditions}

Yuhei Umeda ( $\nabla$ umeda-yuhei@okayama-u.ac.jp )

Okayama University https://orcid.org/0000-0002-9676-6603

Keiya Fukui

Osaka University

\section{Toshimori Sekine}

Center for High Pressure Science \& Technology Advanced Research

Marco Guarguaglini

https://orcid.org/0000-0002-2660-7543

Alessandra Benuzzi-Mounaix

Ecole Polytechnique

Nobuki Kamimura

Osaka University

Kento Katagiri

Osaka University https://orcid.org/0000-0001-8913-1047

Ryosuke Kodama

Osaka University

Takeshi Matsuoka

Kohei Miyanishi

RIKEN https://orcid.org/0000-0002-6477-3710

Alessandra Ravasio

Ecole Polytechnique https://orcid.org/0000-0002-2077-6493

\section{Takayoshi Sano}

Osaka University https://orcid.org/0000-0001-9106-3856

Norimasa Ozaki

Osaka University https://orcid.org/0000-0002-7320-9871

\section{Article}

Keywords: Shock response, degassing reactions, calcite, planetary impact conditions, $\mathrm{CaCO} 3$

Posted Date: September 21st, 2020

DOI: https://doi.org/10.21203/rs.3.rs-69385/v1 
License: (c) (i) This work is licensed under a Creative Commons Attribution 4.0 International License. Read Full License 


\section{Abstract}

Calcite $\left(\mathrm{CaCO}_{3}\right)$ as a planetary material is a source to the atmospheric carbon dioxide through degassing by high-velocity impact events. Revealing the behavior of calcite in the extreme pressure and temperature conditions is required to understand the impact-induced degassing phenomena. Here we report laboratory investigations of shock- compressed calcite beyond the impact velocity of $12 \mathrm{~km} / \mathrm{s}$ (faster than escape velocity from the Earth). The present precise shock measurements elucidate the shape of the calcite Hugoniot curve continuously passing through the melting and metallization states up to a pressure of $1000 \mathrm{GPa}$ (=10-million atmospheres) or a corresponding impact velocity of $30 \mathrm{~km} / \mathrm{s}$, allowing us to predict the post-shock residual temperatures and the dominant carbon oxide species in the impact aftermath. These predictions suggest that $\mathrm{CO}$ emission is much more dominant than $\mathrm{CO} 2$ at the impact velocities of $\sim 10 \mathrm{~km} / \mathrm{s}$ and above, affecting the planetary atmospheric chemistry, greenhouse processes, and environmental changes during planetary evolution.

\section{Main Text}

Protoplanets formed by repeated collisions of interplanetary dust and asteroids have firstly a primitive atmosphere consisting of mainly hydrogen and helium, called as a "primary" atmosphere. Such an atmosphere was dissipated soon into the outer space by the solar wind due to light molecules. Later, secondary components such as $\mathrm{H}_{2} \mathrm{O}, \mathrm{CO}_{2}$, and $\mathrm{N}_{2}$ were added into the atmosphere as originated by the degassing of planetary minerals. Carbonate minerals like calcite $\left(\mathrm{CaCO}_{3}\right)$ are considered to have been the major source of the $\mathrm{CO}_{2}$ component ${ }^{1,2}$. The crater chronology of the Moon and the oxygen isotope ratios for zircon indicate that intense meteorite impact events occurred between $\sim 3.8$ and $\sim 4.1$ billion years ago, which is the so-called late heavy bombardment (LHB) period ${ }^{3,4}$. The impact flux on the Earth during the LHB was at least $\sim 10^{3}$ times more than that on the present Earth. Moreover, it is believed that collisions exceeding $10 \mathrm{~km} / \mathrm{s}$ frequently occurred in the LHB period. Therefore, the high-velocity planetary impact-induced degassing of carbonates plays a critical role in the planetary carbon cycle that affects the formation of planetary atmosphere and ocean and the habitability.

Calcite $\left(\mathrm{CaCO}_{3}\right)$ of carbonates is a typical component in chondritic asteroids ${ }^{5}$ and rocky planet surfaces. In fact, the large-scale, catastrophic impact evidence in places abundant in carbonates is visible also on the present Earth as the Chicxulub crater. The shock-compressed calcite behaviors have been investigated only up to $100 \mathrm{GPa}$ pressure, corresponding to an $8 \mathrm{~km} / \mathrm{s}$ impact velocity. In this study, the Hugoniot pressure-density-temperature $(P-\rho-T)$ relation of calcite was precisely determined to $1000 \mathrm{GPa}$ using the decaying shock method, allowing us to predict the post-impact residual temperatures and the degassed greenhouse gas species.

We performed laser shock experiments on targets illustrated in Fig. 1a and obtained the Hugoniot for calcite shocked between 200 and $1000 \mathrm{GPa}$ (Table S1) using the impedance mismatching technique. Typical images recorded by the velocity interferometer system for any reflector (VISAR) for shock velocity 
$\left(U_{S}\right)$ and streak optical pyrometer (SOP) (see Method section) for temperature $(T)$ are shown in Fig. $1 \mathrm{~b}$ and $1 \mathrm{c}$.

Figure $2 \mathrm{a}$ shows the relationship between the shock velocity and the particle velocity $\left(u_{p}\right)$ determined in the present and previous studies. The previous results showed the linear relation; $U_{s}(\mathrm{~km} / \mathrm{s})=(3.71 \pm$ $0.03)+(1.43 \pm 0.01) u_{p}(\mathrm{~km} / \mathrm{s})^{6}$ and the extrapolation is in excellent agreement with the SESAME model. The present results are well-approximated also by a linear relation; $U_{s}(\mathrm{~km} / \mathrm{s})=(3.79 \pm 0.33)+(1.26 \pm$ 0.03) $u_{p}(\mathrm{~km} / \mathrm{s})$. This linear relation appears to shift downwards parallel to the previous linear extrapolation.

From the present $U_{s}-u_{p}$ data, the Hugoniot pressure-density relation was determined through the Hugoniot conservation relations, as shown in Fig. 2b. Our experimental results demonstrate that the SESAME model overestimates shock pressure by more than $100 \mathrm{GPa}$ or density by more than $0.5 \mathrm{~g} / \mathrm{cc}$ when particle velocity is above $\sim 6 \mathrm{~km} / \mathrm{s}$ corresponding to $\sim 12 \mathrm{~km} / \mathrm{s}$ calcite collision velocity. Since the previous experimental data below $100 \mathrm{GPa}$ agree with the SESAME model, the large gap between the present results and the SESAME suggests that any state changes occur with a significant volume change in the 100-200 GPa pressure range.

Figure 3a shows the measured optical reflectivity $(R)$ as a function of the shock pressure. The calcite reflectivity along the decaying shock-velocity history was extracted from the VISAR data. The shock pressure is estimated from the measured shock velocity using the calcite Hugoniot determined in this work. Calcite is found to be reflective over $\sim 200 \mathrm{GPa}$ and the reflectivity steeply increases over $\sim 350 \mathrm{GPa}$ due to the metallization. Similar tendency was observed for shocked quartz and some other insulators.

Figure $3 \mathrm{~b}$ shows the decaying shock pressure-temperature relationship on calcite, including the previous experimental results ${ }^{7}$ and the EOS models ${ }^{8}$. Below $\sim 350 \mathrm{GPa}$, the obtained Hugoniot $P$ - $T$ curve follows the predicted melting line $e^{9}$. The trend of the $P$ - $T$ relationship changes at $\sim 350 \mathrm{GPa}$, suggesting that the melt completion of calcite along its Hugoniot occurs at $350 \mathrm{GPa}$. Above $350 \mathrm{GPa}$, calcite would be an electronically conducting fluid.

The previous experimental results agree with the SESAME model, but not with the ANEOS and PANDA models. These show that the decomposition reaction of calcite into $\mathrm{CaO}$ and $\mathrm{CO}_{2}$ in the solid phase does not appear in Hugoniot as predicted by the ANEOS and PANDA models at $\sim 80 \mathrm{GPa}$, because SESAME model does not consider the decomposition reaction. Sekine et al. suggested that the decomposition of shocked $\mathrm{MgCO}_{3}$ occurred at $107 \mathrm{GPa}$ from their recovery experiment results and the Hugoniot and released state measurements ${ }^{10}$. Considering the binding energies of $\mathrm{MgCO}_{3}$ to $\mathrm{MgO}$ and $\mathrm{CO}_{2}, \mathrm{CaCO}_{3}$ may decompose at slightly higher shock pressure than $\mathrm{MgCO}_{3}$. Due to the melting and this decomposition reaction, therefore, the previous data points may show a small deviation from the SESAME Hugoniot along the predicted melting line of $\mathrm{CaCO}_{3}$. The Hugoniot $P-T$ data in the previous and present studies can be smoothly connected along the melting line. No optical reflectivity observed below $200 \mathrm{GPa}$, as shown 
in Fig.3a, is consistent with the presumption that the melting and the decomposition reaction dominate in the 100-200 GPa pressure range. Finally, in the pressure range of 100-350 GPa along the melt line, the reactions of melting, decomposition, and dissociation of calcite may sequentially occur.

\section{Implications for natural impacts: carrier of atmospheric components}

The adiabatic release paths from Hugoniot state of calcite were calculated using the Mie-Grüneisen equation of state (see Method section) at pressures of 100, 200, and $300 \mathrm{GPa}$ based on our experiments in Fig. 4a (pink, green, and blue diamonds). The Hugoniot temperature $T_{H}$ and the residual (post-shock) temperature $T_{R}$ are shown in Figs. $4 \mathrm{a}$ and $4 \mathrm{~b}$, respectively. After calcite decomposed into $\mathrm{CaO}$ and $\mathrm{CO}_{2}$, the chemical reaction $\mathrm{CO}_{2}=\mathrm{CO}+1 / 2 \mathrm{O}_{2}$ occurs depending on temperature. The $\mathrm{CO} / \mathrm{CO}_{2}$ ratio produced from calcite shocked at 100,200 , and $300 \mathrm{GPa}$ were estimated to be 6,10 , and 11 , respectively, at a total pressure of $1 \mathrm{~atm}$ as a function of the residual temperature according to the equilibrium gas-phase diagram ${ }^{11}$. This result shows that the amount of $\mathrm{CO}$ generated from $\mathrm{CaCO}_{3}$ increases with increasing shock temperature (shock pressure), because $\mathrm{CO}$ is more thermodynamically stable than $\mathrm{CO}_{2}$ at high temperature.

According to the previous sample recovery experimental results, calcite should be completely degassed at shock pressures above $70 \mathrm{GPa}$, although there are some variations in the threshold pressure dependent on the starting material of single crystal or powders and capsuled conditions of open or close system (e.g., $10 \mathrm{GPa}$ and $70 \mathrm{GPa}$ by Lange and Ahrens, 1986; at 30-35 GPa and 45 GPa by Martinez et al., 1995; at $20 \mathrm{GPa}$ and $33 \mathrm{GPa}$ by Ohno et al., 2008, respectively ${ }^{12,13,14}$ ). The numerical simulations of the Chicxulub impact reported the total gas amount by the shock-induced volatilization as $(0.8-7.6) \times 10^{16}$ $\mathrm{mol}^{15,16}$. If the $\mathrm{CO} / \mathrm{CO}_{2}$ ratio from shocked calcite is $\sim 10$ at an impact pressure of $200 \mathrm{GPa}$ (in a case of our results), the amounts of $\mathrm{CO}$ and $\mathrm{CO}_{2}$ gases produced by the impact become (0.7-6.9) $\times 10^{16} \mathrm{~mol}$ and $(0.1-0.7) \times 10^{16} \mathrm{~mol}$, respectively. According to the previous studies using a light-gas gun, the $\mathrm{CO} / \mathrm{CO}_{2}$ from single crystal calcite shocked at peak shock pressures of below $\sim 100 \mathrm{GPa}$ was estimated to be about $0.1^{17}$. The residual temperature of the present study was much higher than those of the previous studies. Kawaragi et al. (2009) reported that a $\mathrm{CO}$ dominant gas $\left(\mathrm{CO} / \mathrm{CO}_{2}=2.02\right)$ increased $\sim 3 \mathrm{~K}$ in temperature compared with that in case of only $\mathrm{CO}_{2}$ in the Chicxulub impact event ${ }^{18,19}$. CO is known to produce $\mathrm{CH}_{4}$ and tropospheric $\mathrm{O}_{3}$ with the strong greenhouse effect through photochemical reactions and has more intense indirect-radiative-forcing to the heat uptake than $\mathrm{CO}_{2}{ }^{20}$. Our results suggest that the indirect greenhouse effect of $\mathrm{CO}$ should be taken into account in considering the climate change after the high-speed planetary impact events.

Figure $4 \mathrm{~b}$ shows that $\mathrm{CO} / \mathrm{CO}_{2}$ ratio in released gas from calcite and the residual temperature as a function of impact pressure. The collision velocity required to generate shock pressures of 100-300 GPa was calculated to be $7-14 \mathrm{~km} / \mathrm{s}$ for ordinary chondrites ${ }^{21}$. These velocities are typical in planetary impacts $^{22}$. The results suggest the $\mathrm{CO}$ gas was produced more significantly in large-scale planetary 
impacts than the previously estimated. In natural impacts, CO production proceeds more efficiently than our experimental conditions, since meteorites should relatively increase temperature due to certain amounts of porosity ${ }^{23}$. Especially, it is possible that more $\mathrm{CO}$ than expected had been supplied on the Earth by planetary impacts during the LHB period.

Our results may prompt a reconsidering of whole planetary evolution processes on the planetary surface, especially the estimation of the atmospheric compositions and the greenhouse effect, and the seawater temperature. Furthermore, a large amount of $\mathrm{CO}$ generated from impacted carbonate rocks may contribute to model the global warming, the planetary atmosphere chemistry, and the biological mass extinction ${ }^{24}$ on the Earth triggered by bolide impacts.

\section{Declarations}

\section{Acknowledgements}

Laser-shock experiments were conducted under the joint research project of the Institute of Laser Engineering, Osaka University. The authors thank Y. Kimura for her support with target fabrication. This work was supported by grants from MEXT Quantum Leap Flagship Program (MEXT Q-LEAP) grant no. JPMXS0118067246, Japan Society for the Promotion of Science (JSPS) KAKENHI (grant nos. 19K21866 and 16H02246), and Genesis Research Institute, Inc. (Konpon-ken, Toyota).

\section{Author contributions}

Y.U., K.F. and N.O. conceived the project. Y.U. and K.F. designed and manufactured the targets. Y.U., K.F., T.S., M.G., N.K., K.K., R.K., T.M., K.M., T.S. and N.O. conducted the experiments. Y.U., K.F. and N.K. analyzed the data. Y.U., T.S. and N.O. wrote the manuscript. All authors discussed the results and commented on the manuscript.

\section{Competing financial interests}

The authors declare no competing financial interests.

\section{Additional Information}

Supplementary information is available for this paper at https://www.nature.com/nastron/

\section{References}

1. Grieve, R.A.F., P. B. Robertson, (1979), The terrestrial cratering record 1. Current status of observations. Icarus, 38, 212-229.

2. Hildebrand, A.R., G. T. Penfield, D. A. Kring, M. Pilkington, A. Z. Camargo, S. B. Jacobnsen, W. V. Boynton, (1991), Chicxulub crater: a possible Cretaceous/Tertiary boundaryimpact crater on the Yukatan Peninsula, Mexico. Geology, 19, 867-871. 
3. Culler, T. S., T. A., Becker, R. A., Muller, P. R., Renne, (2000), Lunar impact history from 40Ar/39Ar dating of glass spheres. Science, 287, 1785-1788.

4. Valley, J. W., W. H. Peck, E. M. King, and S.A. Wilde, (2002), A cool early Earth. Geology, 30, 351-354.

5. Leuw, S., A. E., Rubin, and J. T., Wasson, (2010), Carbonates in CM chondrites: Complex formational histories and comparison to carbonates in $\mathrm{Cl}$ chondrites,Meteoritics \& Planetary Science,45, 513-530.

6. Kalashnikov, N. G., M. N. Pavlovskiy, G. V. Simakov, and R. F. Trunin, (1973), Dynamic compressibility of calcite-group minerals, Izv. Earth Physics, 2, 23-29.

7. Gupta, S.C., S. G. Love, and T. J. Ahrens, (2002), Shock temperature in calcite $\left(\mathrm{CaCO}_{3}\right)$ at $95-160$ GPa. Earth Planet. Sci. Lett., 201, 1-12.

8. Kerley, G. I., (1989), Equations of state for calcite minerals. I. theoretical model for dry calcium carbonate, High Pressure Research, 2(1), 29-47.

9. Wünnemann, K., G.S. Collins, G.R. Osinski (2008), Numerical modelling of impact melt production in porous rocks, Earth and Planetary Science Letters 269, 530-539.

10. Sekine, T., H. He, T. Kobayashi, and A. Yamaguchi, (2006), Hugoniot and impact-induced phase transition of magnesite. American Mineralogist, 91, 1802-1806.

11. Kress, M. E. and C. P. McKay, (2004), Formation of methane in comet impacts: implications for Earth, Mars, and Titan, Icarus, 168, 475-483.

12. Lange, M. A., and T. J. Ahrens, (1986), Shock-induced $\mathrm{CO}_{2}$ loss from $\mathrm{CaCO}_{3}$; implications for early planetary atmosphere, Earth Planet. Sci. Lett., 77, 409-418.

13. Martinez, I., A. Deutsch, U. Schä rer, P. Ildefonse, F. Guyot, P. Agrinier, (1995), Shock recovery experiments on dolomite and thermodynamical calculations of impact induced decarbonation, $\mathrm{J}$. Geophys. Res., 100, 15465-15476.

14. Ohno, S., T. Kadono, K. Ishibashi, K. Kawaragi, S. Sugita, E. Nakamura, and T. Matsui, (2008), Direct measurements of impact devolatilization of calcite using a laser gun, Geophys. Res. Lett., 35, L13202, http://dx.doi.org/10.1029/2008GL033796.

15. Pope, K.O., K. H. Baines, A. C. Ocampo, and B. A. Ivanov, (1997), Energy, volatile production, and climatic effects of the Chicxulub Cretaceous/Tertiary impact, J. Geophys. Res., 102, 21645-21664.

16. Pierazzo, E., D. A. Kring, and H. J. Melosh, (1998), Hydrocode simulation of the Chicxulub impact event and the production of climatically active gases, J. Geophys. Res., 103, 28607-28625.

17. Kurosawa, K., S. Ohno, S. Sugita, T. Mieno, T. Matsui, and S. Hasegawa, (2012), The nature of shockinduced calcite $\left(\mathrm{CaCO}_{3}\right)$ devolatilization in an open system investigated using a two-stage light gas gun, Earth Planet. Sci. Lett., 337-338, 68-76.

18. Kawaragi, K., Y. Sekine, T. Kadono, S. Sugita, S. Ohno, K. Ishibashi, K. Kurosawa, T. Matsui, S. Ikeda, (2009), Direct measurements of chemical composition of shock-induced gases from calcite: an intense global warming after the Chixulub impact due to the indirect greenhouse effect of carbon monoxide, Earth Planet. Sci. Lett., 282, 56-64. 
19. Gulick, S.P.S., P. J. Barton, G. L. Christeson, J. V. Morgan, M. McDonald, K. M. Cervantes, Z. F. Pearson, A. Surendra, J. U. Fucugauchi, P. M. Vermeesch, and M. R. Warner, (2008), Importance of pre-impact crustal structure for the asymmetry of the Chicxulub impact crater. Nat. Geosci., 1, 131-135.

20. Daniel, J.S., and S. Solomon, (1998), On the climate forcing of carbon monoxide. J. Geophys. Res. $103,13249-13260$.

21. Zhang, F., and T. Sekine, (2007), Impact-shock behavior of Mg- and Ca-sulfates and their hydrates, Geochim. Cosmochim. Acta., 71, 4125.

22. Arakawa, M., M. Yasui, and Y. Shimaki, (2014), High-Velocity Impact Phenomena in the Solar System Related to the Origin and Evolution of Planets, Review of High Pressure Science and Technology, 24(1), 13-20.

23. Bischoff, A., M. Horstmann, A. Pack, M. Laubenstein, and S. Haberer, (2010), Asteroid 2008 TC3Almahata Sitta: A spectacular breccia containing many different ureilitic and chondritic lithologies. Meteoritics \& Planetary Science, 45(10-11), 1638-1656.

24. Ohno, S., T. Kadono, K. Kurosawa, T. Hamura, T. Sakaiya, K. Shigemori, Y. Hironaka, T. Sano, T. Warari, K. Otani, T. Matsui, and S. Sugita, (2014), Production of sulphate-rich vapour during the Chicxulub impact and implications for ocean acidification. Nature Geoscience, 7(4), 279-282.

25. Sekine, T., et al. (2016), Shock compression response of forsterite above 250 GPa, Sci. Adv., 2, e1600157, doi:10.1126/sciadv.1600157.

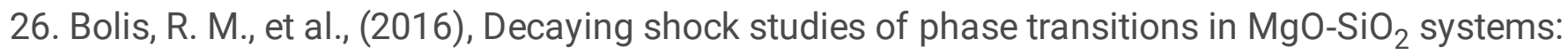
Implications for the super-Earths' interiors. Geophysical Research Letters, 43(18), 9475-9483.

27. Barker, L. M., and R. E. Hollenbach, (1972), Laser interferometer for measuring high velocities of any reflecting surface, J. Appl. Phys., 43, 4669-4775.

28. Miller, J. E., T. R. Boehly, A. Melchior, D. D. Meyerhofer, P. M. Celliers, J. Eggert, D. G. Hicks, C. M. Sorce, J. A. Oertel, and P. M. Emmel, (2007), Streaked optical pyrometer system for laser-driven shock-wave experiments on OMEGA. Review of Scientific Instruments, 78(3), 034903.

29. Hicks, D. G., T. R. Boehly, J. H. Eggert, J. E. Miller, P. M. Celliers, and G. W. Collins (2006), Dissociation of liquid silica at high pressures and temperatures, Phys. Rev. Lett., 97(2), 3-6, doi:10.1103/PhysRevLett.97.025502.

30. Celliers, P. M., G.W. Collins, D. G. Hicks, and J. H. Eggert (2005), Systematic uncertainties in shockwave impedance-match analysis and the high- pressure equation of state of Al, J. Appl. Phys., 98, 113529.

31. Knudson, M. D., R. W. Lemke, D. B. Hayes, C. A. Hall, C. Deeney, and J. R. Asay (2003), Near-absolute Hugoniot measurements in aluminum to $500 \mathrm{GPa}$ using a magnetically accelerated flyer plate technique, Journal of Applied Physics, 94, 4420, doi: 10.1063/1.1604967.

32. Knudson, M. D., and M. P. Desjarlais, (2009), Shock Compression of Quartz to 1.6 TPa: Redefining a Pressure Standard, Phys. Rev. Lett., 1003, 225501, doi: 10.1103/PhysRevLett.103.225501. 
33. Zeldovich, Y. B., and Y. P. Raizer (1967), Physics of Shock Waves and High-Temperature Hydrodynamic Phenomena, Academic, New York.

34. Eggert, J., S. Brygoo, P. Loubeyre, R. S. McWilliams, P. M. Celliers, D. G. Hicks, T. R. Boehly, R. Jeanloz, and G. W. Collins, (2008), Hugoniot Data for Helium in the lonization Regime, Phys. Rev. Lett. 100, 124503.

35. Celliers, P. M., P. Loubeyre, J.H. Eggert, S. Brygoo, R.S. McWilliams, D.G. Hicks, T.R. Boehly, R. Jeanloz, and G.W. Collins (2010). Insulator-to-conducting transition in dense fluid helium. Physical Review Letters, 104(18), 184503.

36. Millot, M., N. A. Dubrovinskaia, A. Cernok, S. Blaha, L. S. Dubrovinsky, D. G. Braun, P. M. Celliers, G. W. Collins, J. H. Eggert, and R. Jeanloz, (2015), Shock compression of stishovite and melting of silica at planetary interior conditions, Science, 347(6220), 418, doi:10.1126/ science.1261507.

37. Knudson, M. D., and M. P. Desjarlais, (2013), Adiabatic release measurements in a-quartz between 300 and $1200 \mathrm{GPa}$ : Characterization of a-quartz as a shock standard in the multimegabar regime, Physical Review B, 88, 184107.

38. Anderson, O. L., (2000), The Grüneisen ratio for the last 30 years, Geophys. J. Int., 143, 279-294.

39. Raikes, S. A., and T. J. Ahrens, (1979), Post-shock temperatures in minerals, Geophys. J. R. astr. Soc., $58,717-747$.

\section{Materials And Methods}

\section{Hugoniot and temperature data of calcite}

The Hugoniot relations on calcite have been determined experimentally at pressure below $95 \mathrm{GPa}^{6}$. On the other hand, only the theoretical model (SESAME 7331) is available at pressures above $200 \mathrm{GPa}$, and there are some data on the $U_{s}-u_{p}$ relations from the calculation models (SESAME, ANEOS, and PANDA ${ }^{8}$, ${ }^{16}$ ). Thus, we require experimental data above $100 \mathrm{GPa}$ to understand the dynamic behaviors in natural impacts. Extreme pressure and temperature conditions over $200 \mathrm{GPa}$ and $5000 \mathrm{~K}$ will be generated at impact velocities of chondritic meteorites over $10 \mathrm{~km} / \mathrm{s}$ using the Hugoniot relations ${ }^{21,25,26}$.

The shock temperature on calcite was measured up to a pressure of $160 \mathrm{GPa}$ in the previous study using gas gun ${ }^{7}$. Temperature data of shocked calcite above $200 \mathrm{GPa}$ are required to understand the reactions on calcite. Extrapolations of the temperature calculations by the ANEOS and PANDA models showed high temperatures relative to the SESAME data at high pressure over $100 \mathrm{GPa}$. For example, the temperatures at $300 \mathrm{GPa}$ by the ANEOS and the PANDA models are $8000 \mathrm{~K}$ and $3000 \mathrm{~K}$ lower than that by the SESAME model, respectively.

\section{Laser shock experiments and optical measurements of pressure and temperature}

The laser shock experiments on calcite were conducted with GEKKO XII laser facility at Osaka University. The GEKKO facility is a neodymium-doped glass laser (the basic wavelength: $\omega 1053 \mathrm{~nm}$ ) system. The 
total 12 beams of three $2 \omega$ beams with a diameter of $1000 \mu \mathrm{m}$ and nine $3 \omega$ beams with a diameter of $600 \mu \mathrm{m}$ were used in this experiment. The temporal shape of the laser pulse was approximately square with a 2.5 ns duration [full width at half-maximum (FWHM)] and rise and fall times of $100 \mathrm{ps}$ each. The total energy and intensity of laser were $300-800 \mathrm{~J}$ and $10^{12}-10^{13} \mathrm{~W} / \mathrm{cm}^{2}$ on the target in the present study, respectively.

We used $\sim 1 \mathrm{~cm}$ natural single crystals of calcite $\mathrm{CaCO}_{3}$ (density: $2.71 \mathrm{~g} / \mathrm{cm}^{3}$ ). The crystals were polished to be $4 \mathrm{~mm}$ square plates ( $500 \mu \mathrm{m}$ thick) by a manufacture. The target assemblage used in the present study is shown in Fig. 1a. All materials of the target were glued with an ultraviolet curing resin. Typical resin was $\sim 1 \mu \mathrm{m}$ thick.

Shock velocity and the thermal emission at the shock wave front of samples were measured by using the Velocity Interferometer System for Any Reflector (VISAR) ${ }^{27}$ and Streak Optical Pyrometer (SOP) ${ }^{28}$, respectively. As quartz becomes a high optical reflectance above $150 \mathrm{GPa}^{29}$, we can measure the shock velocity. And if calcite becomes reflective at high shock pressure, we can measure both shock velocities on the target simultaneously. Although refractive index of a crystal varies with the crystal orientation, the refractive index used in the present study is 1.66 and 1.55 for calcite and quartz, respectively. Velocity sensitivities [velocity per fringe (VPF)] of two line-imaging VISARs (line-VISARs) in this study were 7.39 and $4.47 \mathrm{~km} / \mathrm{s}$ in vacuum. Based on the quartz $U_{s}$ measured by VISAR, the pressure $(P)$, particle velocity $\left(u_{p}\right)$, and $U_{s}$ for Al were obtained by the impedance matching for the interface between Al and quartz. The experimental error of a shock velocity was less than $5 \%$ of the velocity sensitivities.

After that, the $u_{p}$ of calcite was determined by the impedance mismatching method ${ }^{30}$ for the interface between $\mathrm{Al}$ and calcite. The $U_{s}(\mathrm{~km} / \mathrm{s})-u_{p}(\mathrm{~km} / \mathrm{s})$ relations used for quartz and Al are $U_{s}=(6.26 \pm 0.35)+$ $(1.20 \mp 0.02) u_{p}-(2.56 \mp 0.15) u_{p} \exp \left[-(0.37 \pm 0.02) u_{p}\right]$ and $U_{s}=(6.375 \pm 0.25)+(1.18 \pm 0.03) u_{p}$ respectively ${ }^{31,32}$. Shock pressure and density $(\rho)$ in calcite were determined from the $U_{s}$ and $u_{p}$ using the basic conservation relations ${ }^{33}$. Uncertainties in impedance mismatching method were propagated through a Monte Carlo method ${ }^{34}$, hence one-sigma uncertainties were taken to be standard deviation of the distributions. In addition, the reflectivity of shocked calcite was simultaneously obtained from VISAR measurements at the probe laser $(532 \mathrm{~nm})$. The reflectivity of shocked quartz was cited from a reference ${ }^{35}$.

The SOP measures the thermal emission from the shock around a 455-nm wavelength with a narrow bandwidth (38-nm FWHM). The brightness temperature is determined using the gray-body Planck spectrum:

$$
L(\lambda, T)=\varepsilon \frac{2 h c^{2}}{\lambda^{5}}\left(e^{\frac{h c}{\lambda k_{B} T}}-1\right)^{-1}
$$


where $h$ is Planck's constant, $c$ is the speed of light, $\lambda$ is the wavelength of the radiation, $T$ is the temperature of the Planckian source, $K_{B}$ is the Boltzmann constant, and $\varepsilon$ is the emissivity of the shocked matter. This equation can be reduced to a practical form at the narrow band wavelengths ${ }^{28}$, as described by Miller et al. (2007).

$$
T=\frac{T_{0}}{\ln \left(\frac{A \varepsilon}{C}+1\right)}
$$

where $T_{0}$ and $A$ are calibration parameters that depend on the SOP optical system and $C$ is the CCD (charge-coupled device) counts obtained by the streak camera system. The emissivity $\varepsilon$ is calculated from the Kirchhoff law, $\varepsilon=1-R$, where $R$ is the shock-front reflectivity. We used quartz as the standard material because the relations between $T-U_{S}$ and $R-U_{S}$ have been precisely measured ${ }^{29,}{ }^{36}$. We determined the value of $A$ from several calibration shots on quartz to measure $U_{S}$ and SOP simultaneously. More details of the SOP measurement can be found in the previous studies ${ }^{25,26}$.

\section{Estimation of an adiabatic release state}

The adiabatic release state of shocked calcite was determined to estimate the residual temperature at pressure release. Release isentrope was approximated by using Mie-Grüneisen equation of state ${ }^{37}$. At first, the following Eq. (1) was given by combining the Rankine-Hugoniot equations with Mie-Grüneisen EOS

$$
P_{S}(V)=P_{H}(V)\left[1-\frac{\Gamma}{2 V}\left(V_{0}-V\right)\right]+\frac{\Gamma}{V}\left[E_{S}(V)-E_{0}\right]
$$

where $P, E$ and $V$ are the pressure, internal energy and the specific volume, respectively. Grüneisen parameter $\Gamma$ was assumed to be a function of $V$ only, using $\Gamma_{0}=0.57^{38}$,

$$
\Gamma=\Gamma_{0} \frac{V}{V_{0}}
$$

The subscript $H, S$, and 0 denote the reference Hugoniot, release adiabat, and the initial state, respectively. The internal energy on an isentrope was determined by solving the ordinary differential equation (ODE), which gives

$$
\begin{aligned}
E_{s}-E_{0}= & \exp \left[\frac{\Gamma_{0}}{V_{0}}\left(V_{1}-V\right)\right]\left\{\frac{P_{1}\left(V_{0}-V_{1}\right)}{2}\right. \\
& \left.-\int_{V_{1}}^{V} P_{H}\left[1-\frac{\Gamma_{0}}{2 V_{0}}\left(V_{0}-V^{\prime}\right)\right] \times \exp \left[\frac{\Gamma_{0}}{V_{0}}\left(V^{\prime}-V_{1}\right)\right] d V^{\prime}\right\}
\end{aligned}
$$


where subscript 1 refers to shocked state. Substituting Eq. (3) into Eq. (1), we determined the adiabatic release state of calcite using the measured $P_{1}, V_{1}$, and the obtained calcite Hugoniot.

The residual (post-shock) temperature $T_{R}$ was given by Eq. (4) ${ }^{39}$

$$
T_{R}=T_{1} \exp \left(\int_{V_{1}}^{V_{2}} \frac{\Gamma\left(V^{\prime}\right)}{V^{\prime}} d V^{\prime}\right)
$$

where $T_{1}$ and $V_{2}$ denote the initial shocked temperature and residual specific volume, respectively.

\section{Figures}
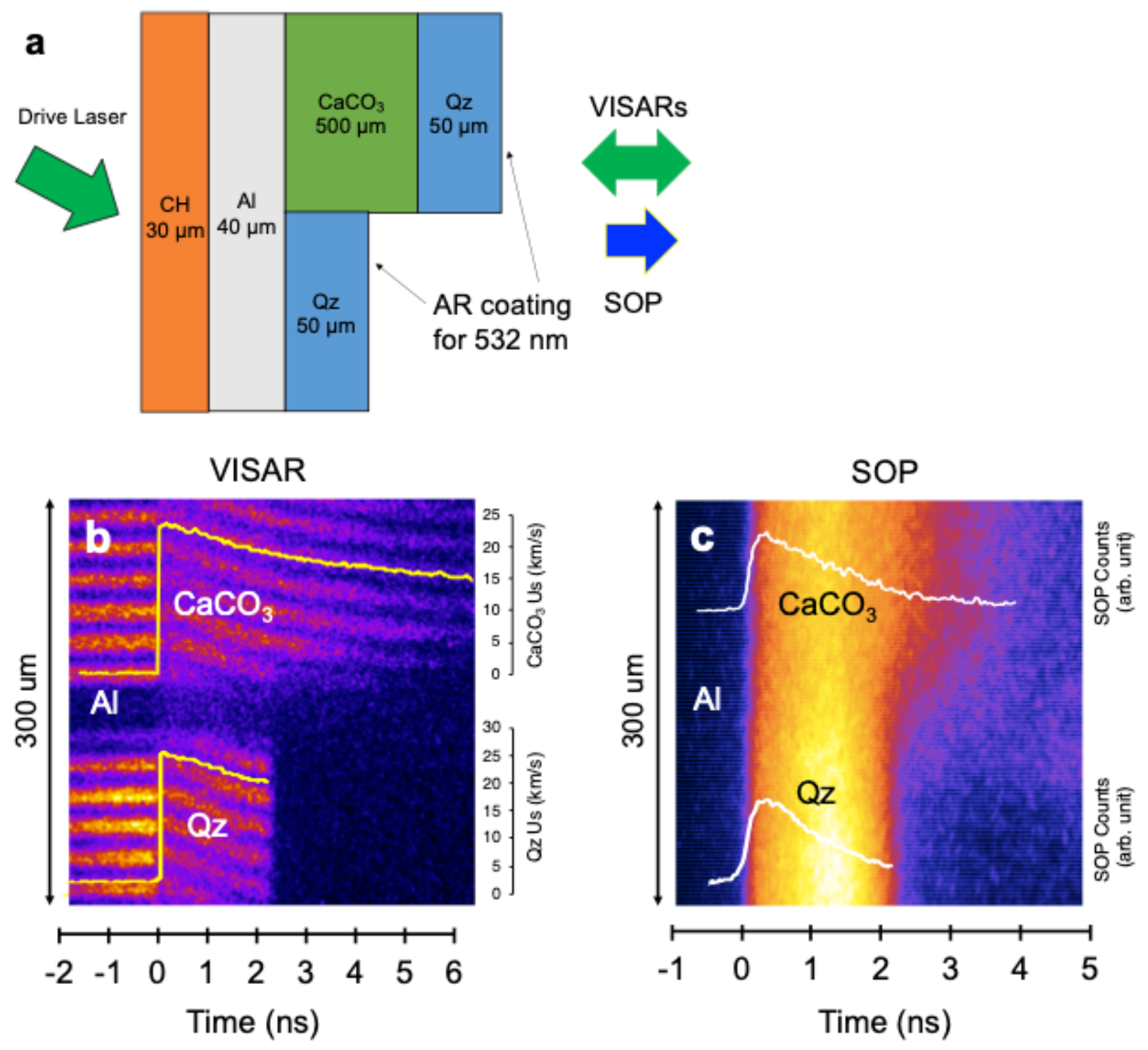

Figure 1 
Schematic setup and typical measurements by VISAR and SOP in laser shock experiments. a, The target assembly consisted of poly-propylene (CH), aluminum (Al), crystalline a-quartz (Qz), and calcite (CaCO3) from the drive laser side (GEKKO XII). The thickness was 30, 40, 50, and $500 \mu \mathrm{m}$ for $\mathrm{CH}, \mathrm{Al}, \mathrm{SiO} 2$, and $\mathrm{CaCO} 3$, respectively. The $\mathrm{CH}$ was used as an ablator to generate a shock wave, and $\mathrm{Al}$ as the base plate, and $\mathrm{SiO} 2$ as the reference material for the impedance mismatching analysis and the temperature determination. The VISAR side of $\mathrm{SiO} 2$ was coated with an anti-reflected (AR) layer for a probe laser at the wavelength of $532 \mathrm{~nm}$. Since AR coating could not be available for calcite and SiO2 has almost the same refractive index with calcite., the last $\mathrm{SiO} 2$ after calcite was used for the window material. $\mathrm{b}$ and $\mathrm{c}$, VISAR line-imaging velocity record and inferred shock velocity (yellow curve, scale on right).

Corresponding SOP raw image and count profiles considering the emissivity (1-R) (white curve). The time zero is set to the arrival time of shock wave on the $\mathrm{Al} / \mathrm{CaCO} 3$ and $\mathrm{Al} / \mathrm{Qz}$ interfaces. The vertical width in images is about $300 \mu \mathrm{m}$.
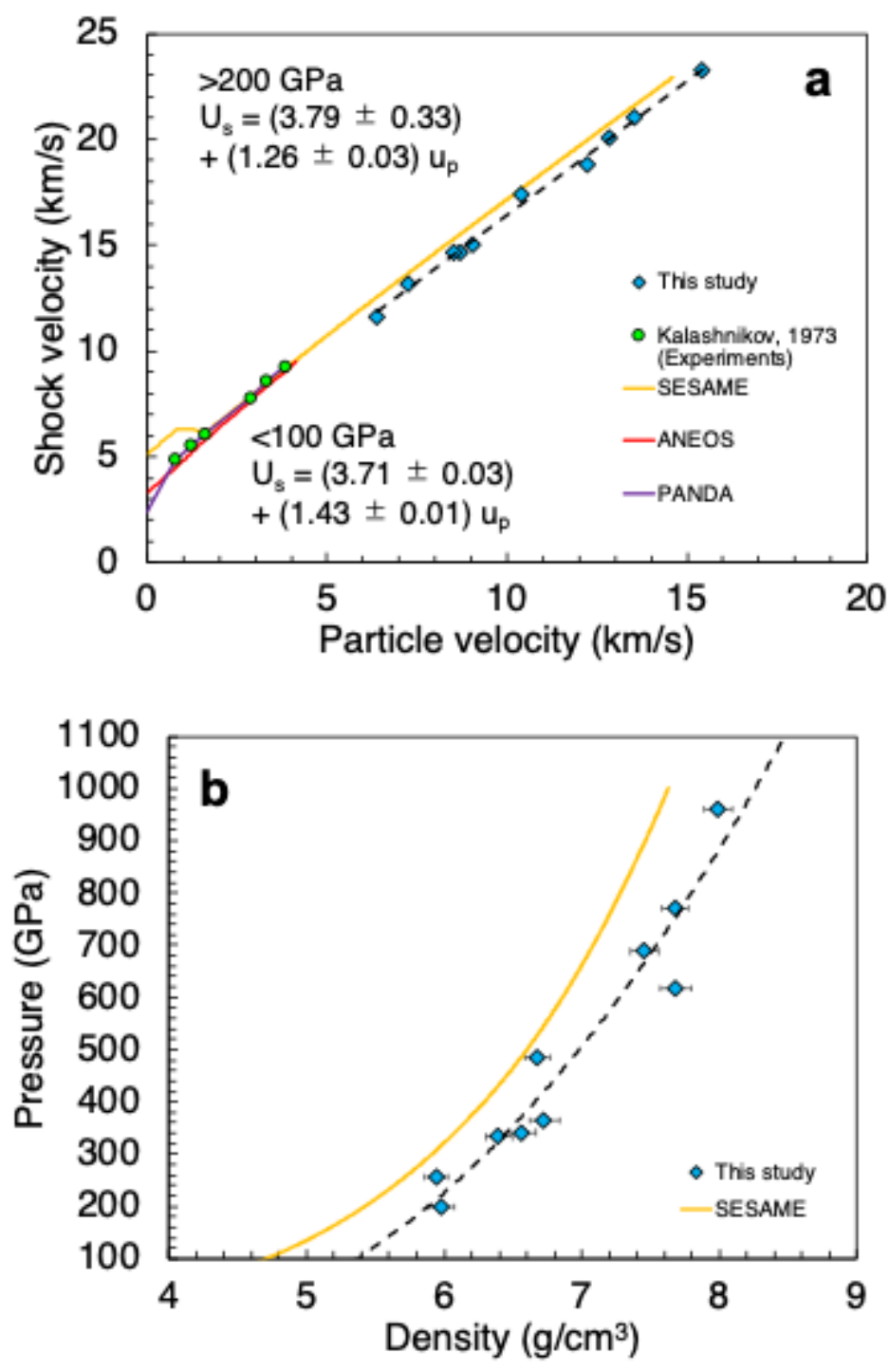

Figure 2 
Hugoniot relations of calcite. a, The Us-up data of this study are shown as light blue diamonds and connected linearly as the broken line. The error bars of this study are smaller than the symbol size. The open green circles indicate the experimental result 6 by Kalashnikov, (1973). The orange, red, and purple solid lines represent SESAME, ANEOS, and PANDA models, respectively $8,16 . \mathrm{b}$, The pressure-density data determined in this study are shown as light blue diamonds and connected by the broken curve, and compared with the SESAME model as orange solid curve.
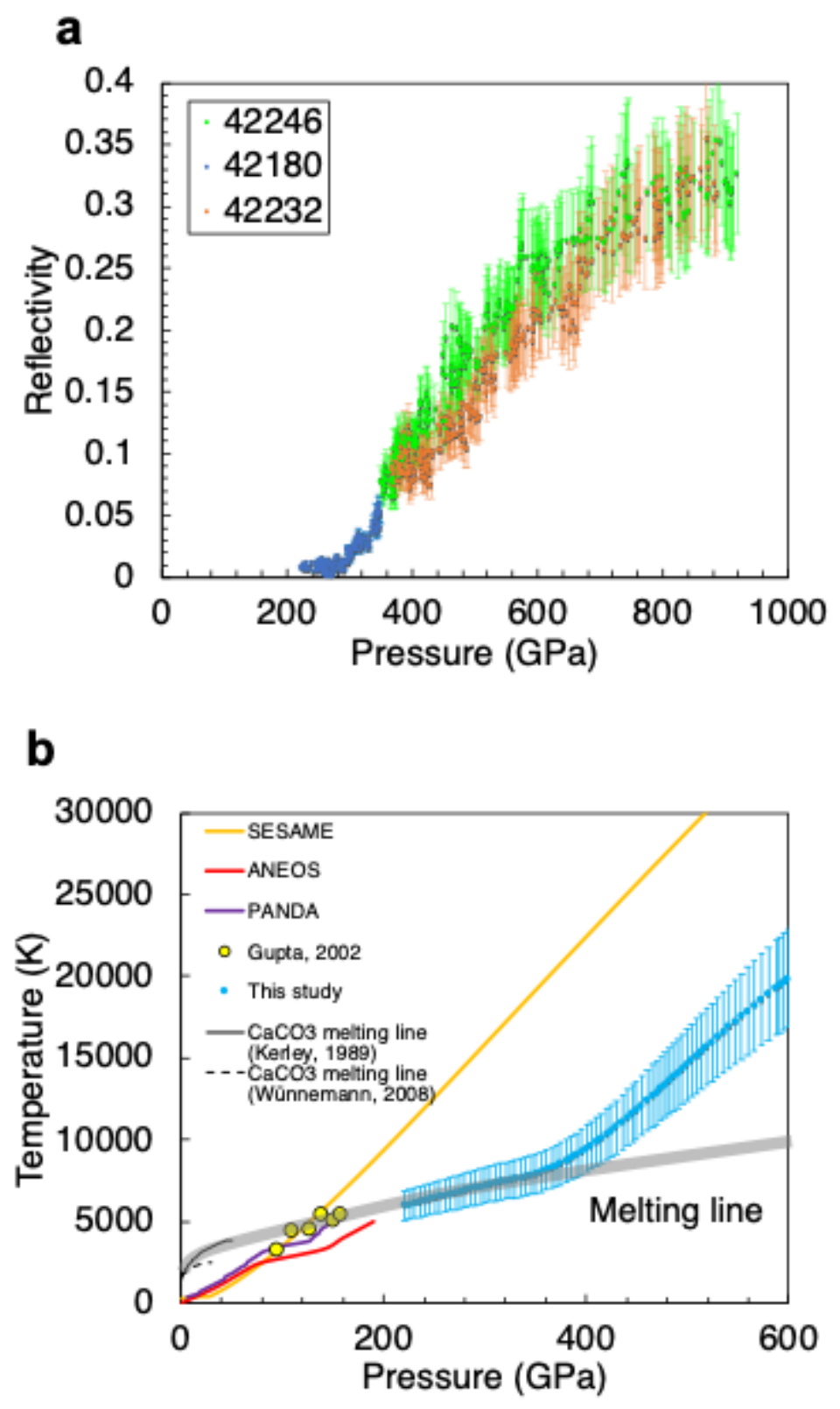

Figure 3

The reflectivity at $532 \mathrm{~nm}$ and the temperature as a function of pressure. a, The green, blue, and orange plots are shots 42246,42180 , and 42232 , respectively. b, The light blue plots indicates our result from the decaying shock experiment. The orange, red, and purple solid lines represent SESAME, ANEOS, and PANDA models, respectively 8,16 . The open yellow circles indicate the experimental results 7 . The solid 
and dotted black line mean the calcite melt lines at low pressures 8,9 . The grey bold line indicates the calcite melting line proposed by this study.
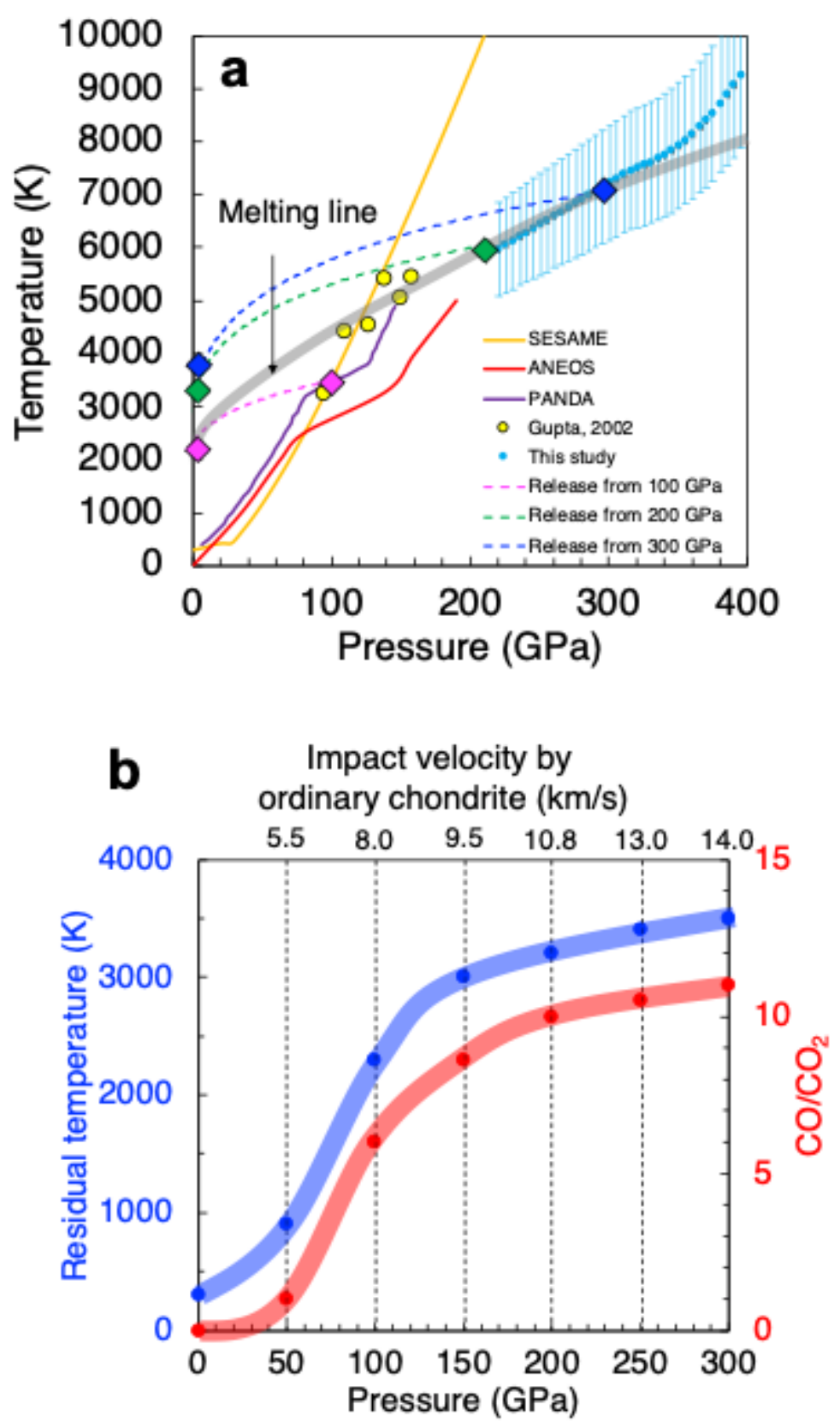

Figure 4

The release isentrope and the residual temperature and the $\mathrm{CO} / \mathrm{CO} 2$ ratio of shocked calcite as a function of pressure (impact velocity). a, The release isentrope paths (dotted lines) of shocked calcite from 100, 200 , and $300 \mathrm{GPa}$ in the magnification of Fig. 3b. The diamonds of pink, green, and blue mean the start and the end points of releasing. $b$, The residual temperature (blue; left axis) and the $\mathrm{CO} / \mathrm{CO} 2$ ratio (red; right axis) as a function of pressure. The impact velocity was calculated using the Us-up for the ordinary 
chondrite 21 proposed from Zhang and Sekine, (2007) at the vertical impact. The CO/CO2 ratio was estimated using the equilibrium gas-phase diagram as a function of temperature 11.

\section{Supplementary Files}

This is a list of supplementary files associated with this preprint. Click to download.

- v2NatComEarthUmedacalciteSM.docx 